\title{
Phosphotungstic heteropoly acid as efficient heterogeneous catalyst for solvent-free isomerization of $\alpha$-pinene and longifolene
}

\author{
Kelly A. da Silva Rocha a , Patricia A. Robles-Dutenhefner ${ }^{\mathrm{a}, 1}$, Ivan V. Kozhevnikov ${ }^{\mathrm{b}}$, Elena V. Gusevskaya ${ }^{\mathrm{a}, *}$ \\ a Departamento de Química, Universidade Federal de Minas Gerais, Av Antonio Carlos 6627, 31270-901 Belo Horizonte, Minas Gerais, Brazil \\ ${ }^{\mathrm{b}}$ Department of Chemistry, University of Liverpool, Liverpool L69 7ZD, UK
}

\section{A R T I C L E I N F O}

\section{Article history:}

Received 3 June 2008

Received in revised form 2 October 2008

Accepted 6 October 2008

Available online 11 October 2008

\section{Keywords:}

Isomerization

Terpenes

Acid catalysis

Heteropoly acid

\begin{abstract}
A B S T R A C T
Silica-supported $\mathrm{H}_{3} \mathrm{PW}_{12} \mathrm{O}_{40}(\mathrm{PW})$, the strongest heteropoly acid in the Keggin series, is an efficient, environmentally friendly heterogeneous catalyst for the liquid-phase isomerization of $\alpha$-pinene and longifolene into their more valuable isomers - camphene and isolongifolene, respectively, which are intermediates in the synthesis of expensive fragrances. The reactions occur under solvent-free conditions in the temperature range of $80-100^{\circ} \mathrm{C}$, with low catalyst loadings $(0.15-5 \mathrm{wt} \%)$ and high turnover numbers (up to 6000 per proton). The catalyst can be easily recovered and reused. No PW leaching is observed in the reaction system.
\end{abstract}

(c) 2008 Elsevier B.V. All rights reserved.

\section{Introduction}

The application of clean catalytic technologies, especially those with the use of heterogeneous catalysts, is becoming increasingly important for the development of environmentally benign chemical processes [1]. In this context, catalysis by acids can be considered as one of the most important areas of catalysis. Although the acid catalysis is widely employed in chemical industry, it suffers from the traditional use of hazardous mineral acids resulting in pollution and corrosion problems $[1,2]$.

Heteropoly acids (HPAs), especially those of the Keggin series, have attracted considerable interest as acid catalysts for the clean synthesis of fine and specialty chemicals in homogeneous and especially heterogeneous systems [2-5]. Due to their stronger acidity, HPAs generally exhibit higher catalytic activities compared with conventional catalysts, such as mineral acids, ion-exchange resins, mixed oxides, zeolites, etc. [2-5]. Furthermore, HPA catalysis lacks side reactions, such as sulfonation and chlorination, which frequently occur with mineral acids. HPAs have been reported as efficient homogeneous and/or heterogeneous catalysts for reactions, such as hydration and acetoxylation [6,7], Friedel-

\footnotetext{
* Corresponding author. Tel.: +55 31 34995741; fax: +55 3134995700

E-mail address: elena@ufmg.br (E.V. Gusevskaya).

${ }^{1}$ Present address: Departamento de Química, Universidade Federal de Ouro Preto, 35400-000, Ouro Preto, Minas Gerais, Brazil.
}

Crafts acylation and Fries rearrangement [8-10], etherification $[11,12]$, and isomerization of alkanes $[13,14]$ and alkenes $[14,15]$. We have been interested in catalytic transformations of terpenes to value-added chemicals and, previously, have reported HPAs to be very active and versatile catalysts for the isomerization of terpenic compounds, such as $\alpha$-pinene oxide, citronellal, and $\alpha$-terpineol [16-20].

Terpenes and sesquiterpenes are an important renewable feedstock for flavor and fragrance industries [21-23]. Various terpenic compounds used in the fine chemicals industry are produced by acid-catalyzed transformations of more abundant terpenes and sesquiterpenes. In these reactions, mineral acids are often used as catalysts, in overstoichiometric amounts, which leads to large amounts of waste.

One example of the valorization of terpenes is the isomerization of $\alpha$-pinene to produce camphene, an important intermediate in the synthesis of isoborneol, isobornyl acetate, and camphor, with the latter compound having more commercial applications than any of terpenes [21]. Camphene is available in the nature from essential oils of some plants, but most of camphene is synthesized from $\alpha$-pinene, an inexpensive major constituent (ca. 85\%) of turpentine oils obtained from coniferous trees [21]. Another example is the isomerization of longifolene, one of the most abundant sesquiterpenes which is found in significant amounts $(5-7 \%)$ in the Indian turpentine oil obtained from Chirpine (Pinus longifolia) [24-26]. The longifolene is isomerized into isolongifolene, then transformed to oxygenated derivatives, which because 
of their extremely rich woody and floral odor occupy a vintage place in the perfumery industry [24-26].

Both processes mentioned above have gained considerable attention of catalytic chemists due to their industrial significance. The commercial production of camphene from $\alpha$-pinene is based on the use of a weakly acidic $\mathrm{TiO}_{2}$ catalyst [27]. Many other solid acid catalysts have been tested for this reaction, such as zeolites [28-30], activated clays [31,32], sulfated zirconia [33], and ion exchange resins [34]. Supported HPAs have been tested recently as well $[35,36]$. Typically, $30-50 \%$ yields of camphene together with a complex mixture of other monoterpene by-products have been obtained. Isolongifolene is traditionally produced from longifolene through a lengthy, multi step procedure using soluble acids as catalysts $[37,38]$. In recent years, solid acid catalysts, such as sulfated zirconia [24,26] and modified clays [26], have been applied to synthesize isolongifolene in higher yields. Nevertheless, the development of more efficient and environment friendly catalysts for $\alpha$-pinene and longifolene isomerization remains a challenge.

We report the application of silica-supported $\mathrm{H}_{3} \mathrm{PW}_{12} \mathrm{O}_{40}(\mathrm{PW})$, the strongest HPA in the Keggin series, as an efficient and recyclable solid catalyst for the skeletal rearrangements of $\alpha$ pinene and longifolene under solvent-free conditions. To our knowledge, no attempt to use HPA catalysts for the latter reaction has been made so far.

\section{Experimental}

\subsection{Chemicals}

All chemicals were purchased from commercial sources and used as received, unless otherwise stated. $\mathrm{H}_{3} \mathrm{PW}_{12} \mathrm{O}_{40}$ hydrate was from Aldrich and Aerosil 300 silica from Degussa. Longifolene and isolongifolene were kindly donated by Professor J.C. Bayón (Universidad Autónoma de Barcelona).

\subsection{Characterization techniques}

${ }^{31} \mathrm{P}$ MAS NMR spectra were recorded at room temperature and $4 \mathrm{kHz}$ spinning rate on a Bruker Avance DSX 400 NMR spectrometer using $85 \% \mathrm{H}_{3} \mathrm{PO}_{4}$ as a reference. Powder X-ray diffraction (XRD) of the catalysts was measured using a Rigaku Geigerflex3034 diffractometer with $\mathrm{Cu} \mathrm{K} \alpha$ radiation. Surface area and porosity of the catalysts were measured by nitrogen physisorption at $77 \mathrm{~K}$ on an Micromeritics ASAP 2000 instrument. Tungsten and phosphorus content in the catalysts was measured by inductively coupled plasma (ICP atomic emission spectroscopy) on a Spectro Ciros CCD spectrometer.
Table 1

Isomerization of longifolene under solvent-free conditions catalyzed by $20 \mathrm{wt} \%$ $\mathrm{H}_{3} \mathrm{PW}_{12} \mathrm{O}_{40} / \mathrm{SiO}_{2}$ (5 wt\%).

\begin{tabular}{cccclc}
\hline Run & Time (min) & $T\left({ }^{\circ} \mathrm{C}\right)$ & Conversion (\%) & Selectivity $^{\mathrm{a}}(\%)$ & TON $^{\mathrm{a}}$ \\
\hline 1 & 300 & 80 & 60 & 95 & 286 \\
$2^{\mathrm{b}}$ & 70 & 100 & 96 & 98 & 457 \\
3 & 10 & 120 & 100 & 76 & 477 \\
\hline
\end{tabular}

a Turnover number: the number of substrate molecules converted per proton in PW

b After reaction, the catalyst was separated by centrifugation and reused 2 times without loss of activity and selectivity.

\subsection{Catalyst preparation and characterization}

The silica-supported catalysts, $20 \mathrm{wt} \% \mathrm{H}_{3} \mathrm{PW}_{12} \mathrm{O}_{40} / \mathrm{SiO}_{2}$ (PW/ $\mathrm{SiO}_{2}$ ), was prepared by impregnating Aerosil 300 (S $\mathrm{S}_{\mathrm{BET}}$, $300 \mathrm{~m}^{2} \mathrm{~g}^{-1}$ ) with an aqueous PW solution and calcined at $130{ }^{\circ} \mathrm{C} / 0.2-0.3$ Torr for $1.5 \mathrm{~h}$, as described elsewhere [39]. The PW content was determined by ICP. The BET surface area was $200 \mathrm{~m}^{2} \mathrm{~g}^{-1}$ and average pore volume $0.53 \mathrm{~cm}^{3} \mathrm{~g}^{-1}$. The integrity of Keggin structure of PW was verified by ${ }^{31} \mathrm{P}$ MAS NMR; the catalysts showed only a single peak at ca. $-15 \mathrm{ppm}$ characteristic of $\mathrm{H}_{3} \mathrm{PW}_{12} \mathrm{O}_{40}$ [5]. From XRD, the catalysts included crystalline phase of PW on the silica surface. The acid strength of silica-supported PW was characterized calorimetrically using ammonia and pyridine adsorption and discussed in the previous work [40].

\subsection{Catalytic reactions}

The reactions were carried out in a glass reactor equipped with a magnetic stirrer at $40-120^{\circ} \mathrm{C}$. In a typical run, a mixture of the substrate $(2.0 \mathrm{~mL})$, dodecane $(0.20 \mathrm{~mL}$, internal standard) and solid PW catalyst (0.15-5.0 wt\%) was intensively stirred under air at a specified temperature. The reaction progress was followed by gas chromatography (GC) using a Shimadzu 17 instrument fitted with a Carbowax $20 \mathrm{M}$ capillary column and a flame ionization detector. At appropriate time intervals, stirring was stopped and after quick catalyst settling aliquots were taken and analyzed by GC. The GC mass balance was based on the substrate charged. The difference was attributed to the formation of oligomers, which were not GC determinable and referred in Tables 1 and 2 as "others". The structures of all products were confirmed by GC co-injections using authentic samples.

To control catalyst leaching and the possibility of a homogeneous reaction, the catalyst was removed by centrifugation of the reaction mixture at the reaction temperature to avoid

Table 2

Isomerization of $\alpha$-pinene under solvent-free conditions catalyzed by $20 \mathrm{wt} \% \mathrm{H}_{3} \mathrm{PW}_{12} \mathrm{O}_{40} / \mathrm{SiO}_{2}$.

\begin{tabular}{|c|c|c|c|c|c|c|c|c|c|c|c|c|}
\hline \multirow[t]{3}{*}{ Run } & \multirow{3}{*}{$\begin{array}{l}\text { Catalyst } \\
(\mathrm{wt} \%)\end{array}$} & \multirow{3}{*}{$\begin{array}{l}T \\
\left({ }^{\circ} \mathrm{C}\right)\end{array}$} & \multirow{3}{*}{$\begin{array}{l}\text { Time } \\
\text { (min) }\end{array}$} & \multirow{3}{*}{$\begin{array}{l}\text { Conversion } \\
(\%)\end{array}$} & \multirow[t]{3}{*}{$\mathrm{TON}^{\mathrm{a}}$} & \multicolumn{7}{|c|}{ Selectivity (\%) } \\
\hline & & & & & & \multicolumn{2}{|c|}{ Tri- and bicyclics } & \multicolumn{4}{|c|}{ Monocyclics } & \multirow[t]{2}{*}{ Others } \\
\hline & & & & & & Tricyclene & Camphene & Limonene & $\alpha$-Terpinene & $\gamma$-Terpinene & Terpino-lene & \\
\hline 1 & 1.5 & 40 & 240 & 96 & 2092 & 3 & 28 & 17 & 4 & 2 & 5 & 42 \\
\hline 2 & 1.5 & 60 & 60 & 98 & 2135 & 21 & 31 & 17 & 6 & 3 & 6 & 16 \\
\hline 3 & 0.60 & 60 & 300 & 95 & 5749 & 9 & 40 & 25 & 6 & 3 & 7 & 10 \\
\hline \multirow[t]{2}{*}{$4^{\mathrm{b}}$} & 0.60 & 100 & 10 & 60 & & 2 & 49 & 31 & 6 & 4 & 8 & - \\
\hline & & & 60 & 90 & 5447 & 4 & 50 & 28 & 7 & 3 & 8 & - \\
\hline 5 & 0.60 & 120 & 30 & 100 & 6052 & 4 & 20 & 4 & - & - & - & 72 \\
\hline 6 & 0.15 & 120 & 60 & 10 & 2178 & - & 50 & 40 & 1 & 1 & 8 & - \\
\hline
\end{tabular}

a Turnover number: the number of substrate molecules converted per proton in PW.

b After reaction, the catalyst was separated by centrifugation and re-used 3 times without loss of activity and selectivity. 


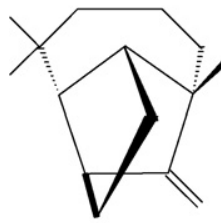

longifolene
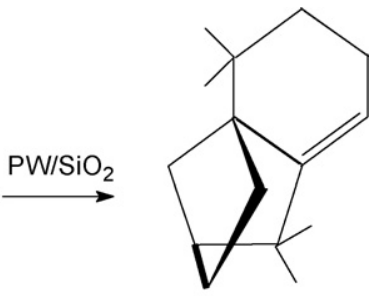

isolongifolene
Scheme 1. Acid-catalyzed isomerization of longifolene.

re-adsorption of active components onto silica, then the supernatant was added with fresh substrate and allowed to react on. No further isomerization was observed in such experiments, indicating absence of PW leaching.

\section{Results and discussion}

\subsection{Isomerization of longifolene}

Our results on the isomerization of longifolene (Scheme 1) are presented in Table 1 . The $\mathrm{PW} / \mathrm{SiO}_{2}$ catalyst showed excellent performance in this reaction. At $80{ }^{\circ} \mathrm{C}$, more than a half of the substrate was transformed into isolongifolene in $5 \mathrm{~h}$ with a selectivity of $95 \%$ (Table 1 , run 1 ). The reaction rate greatly increased with increasing the temperature; at $100^{\circ} \mathrm{C}$, longifolene conversion reached $96 \%$ in 70 min with $98 \%$ selectivity (Table 1 , run 2 ). The selectivity is remarkably high, given the complex mechanism of longifolene isomerization [25]. At $120^{\circ} \mathrm{C}$, the reaction was very fast: a $100 \%$ conversion was achieved in $<10 \mathrm{~min}$; however, the selectivity dropped to $76 \%$ due to the formation of high-boiling products, which were not GC determinable (Table 1 , run 3 ).

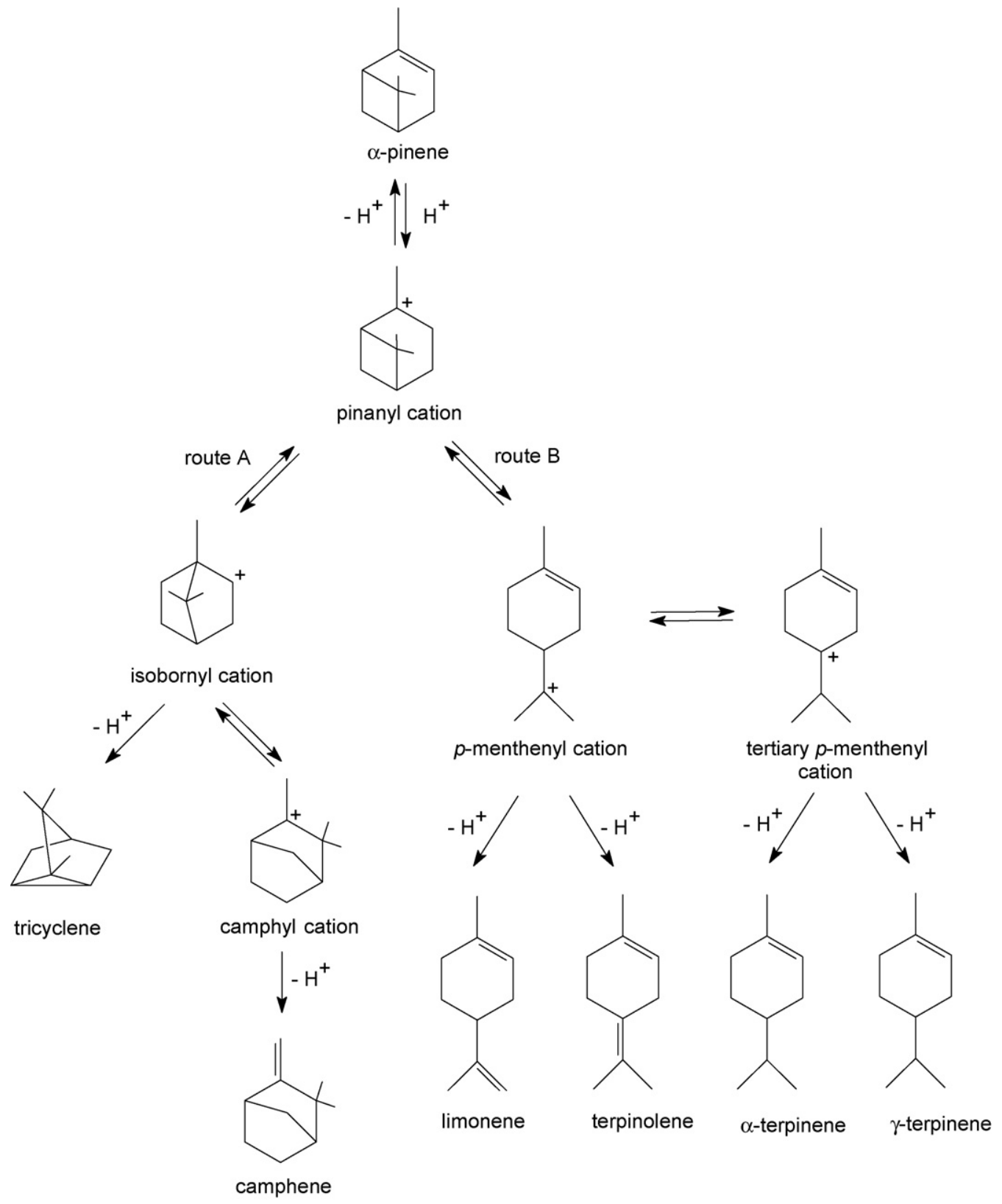

Scheme 2. Acid-catalyzed isomerization of $\alpha$-pinene. 
In blank tests, with no catalyst or pure silica added, practically no reaction was observed at $100{ }^{\circ} \mathrm{C}$. On the other hand, a nearly quantitative yield of isolongifolene was obtained using small amounts of HPA: an average turnover frequency of $7 \mathrm{~min}^{-1}$ and a turnover number of 457 per one HPA proton were attained in run 2. An important advantage is that no solvent was used and the catalyst could be easily separated by filtration or centrifugation. In run 2 , the catalyst was reused two times after washing with hexane without any loss in its activity and selectivity.

Because the HPA is insoluble in non-polar solvents, neither HPA leaching nor any contribution of homogeneous catalysis was expected. To prove this, the catalyst was removed from the reaction system after reaction completion, fresh substrate was added to the supernatant and the reaction was allowed to proceed further. No activity was observed in this experiment, which indicated that PW did not leach from silica into the reaction medium under the conditions used.

\subsection{Isomerization of $\alpha$-pinene}

$\alpha$-Pinene is a very reactive substrate, so that a complex mixture of products is formed in the presence of an acid catalyst, with camphene selectivity being strongly dependent on the reaction conditions and the amount of catalyst [28-36]. Silica-supported PW showed excellent performance in $\alpha$-pinene isomerization (Table 2 ). In the temperature range from $60-100{ }^{\circ} \mathrm{C}$, the selectivity to camphene was $40-50 \%$ at an almost complete conversion (Table 2, runs 3 and 4), matching the best results reported so far. At $60{ }^{\circ} \mathrm{C}$, the reaction was relatively slow, taking about $5 \mathrm{~h}$ to be completed, with $40 \%$ camphene selectivity; whereas at $100{ }^{\circ} \mathrm{C}$, it reached $90 \%$ conversion in $1 \mathrm{~h}$, with $50 \%$ camphene selectivity. The product distribution slightly varied over time. Under optimized conditions, the selectivity to camphene was $50 \%$, with $28 \%$ limonene formed as a main by-product (Table 2, run 4). Minor by-products were tricyclene, $\alpha$-terpinene, $\gamma$-terpinene, and terpinolene (3-8\% each). In total, camphene and limonene accounted for ca. $80 \%$ of the $\alpha$-pinene isomerization products over $\mathrm{PW} / \mathrm{SiO}_{2}$ catalyst. This compares well with most of the reported catalysts, which usually give camphene along with a mixture of up to 10 by-products, each of them in less than $10 \%$ selectivity $[28,32,34,35]$. The $\mathrm{PW} / \mathrm{SiO}_{2}$ catalyst was highly efficient in an amount as low as $0.6 \mathrm{wt} \%$, with a turnover number of 5450 and turnover frequency of $91 \mathrm{~min}^{-1}$ (Table 2, run 4).

No leaching of PW from silica was observed, as the reaction was practically ceased to occur after removing the catalyst from the reaction mixture in run 3 . In run 2 , the catalyst was reused 3 times virtually without loss in activity and selectivity.

The acid-catalyzed transformation of $\alpha$-pinene is likely to occur via a carbenium-ion mechanism, which may be represented by Scheme 2. A great number of mono-, bi-, and tricyclic isomers can be formed in this system. It is generally accepted $[28,30,31,41]$ that the isomerization of $\alpha$-pinene proceeds via two parallel pathways, one of which resulting in bi- and tricyclic products (route A) and the other in monocyclic products (route B). The reaction initiates by protonation of the $\alpha$-pinene double bond to form the pinanyl cation, whose further rearrangement via opening the fourmembered ring results in almost equally stable isobornyl and $p$ menthenyl cations $[31,41]$. The isobornyl cation can lose a proton to directly yield tricyclene. Alternatively, it can isomerize to the camphyl cation to yield camphene. Similarly, the $p$-menthenyl cation can give either limonene and terpinolene by direct deprotonation or $\alpha$-terpinene and $\gamma$-terpinene via rearrangement into the tertiary $p$-menthenyl cation.

It has been suggested that the nature of acid active sites can strongly affect the balance between the two possible routes of isomerization of the pinanyl cation. Camphene and other bi- and tricyclic products are thought to preferentially form on Lewis acid sites, whereas monocyclic products on Brønsted acid sites [2830,33 ]. It is surprising, therefore, that in spite of the strong Brønsted acidity of PW, the reaction occurred with up to 50\% selectivity to camphene at a complete substrate conversion, with almost $80 \%$ combined camphene and limonene selectivity. The effectiveness of the PW catalyst in $\alpha$-pinene isomerization can be related to a weak interaction of the heteropoly anion, which is a very soft base, with carbenium-ion reaction intermediates [3]. The heteropoly anion is unlikely to influence rearrangements of the carbenium-ion intermediates; thus it differs from the anions of conventional Brønsted acids, which usually strongly affect the products, promoting side reactions.

\section{Conclusions}

We have found an efficient and environment-friendly solid acid catalyst, $\mathrm{H}_{3} \mathrm{PW}_{12} \mathrm{O}_{40} / \mathrm{SiO}_{2}$, for the liquid-phase solvent-free isomerization of $\alpha$-pinene and longifolene to respectively camphene and isolongifolene. The catalyst is easy to prepare; it is very active in small amounts (0.15-5 wt\%), exhibiting high turnover numbers (457-5750), stable to leaching under reaction conditions, and can be easily recovered and reused without loss of activity and selectivity. Our synthetic protocols provide simple and clean routes to the industrially important terpenic intermediates for the synthesis of valuable fragrances. Further studies into developing heteropoly acid catalysts for the valorization of renewable resources are underway.

\section{Acknowledgments}

Financial support and scholarships (KASR and PARD) from CNPq, CAPES and FAPEMIG are acknowledged.

\section{References}

[1] J.H. Clark, Pure Appl. Chem. 73 (2001) 103

[2] I.V. Kozhevnikov, Catalysts for Fine Chemicals, Catalysis by Polyoxometalates, Vol. 2, Wiley, Chichester, 2002.

[3] T. Okuhara, N. Muzuno, M. Misono, Appl. Catal. A 222 (2001) 63.

[4] M.N. Timofeeva, Appl. Catal. A 256 (2003) 19.

[5] I.V. Kozhevnikov, Chem. Rev. 98 (1998) 171

[6] P.A. Robles-Dutenhefner, K.A. da Silva, M.R.H. Siddiqui, I.V. Kozhevnikov, E.V. Gusevskaya, J. Mol. Catal. A 175 (2001) 33.

[7] K.A. da Silva, I.V. Kozhevnikov, E.V. Gusevskaya, J. Mol. Catal. A 192 (2003) 129.

[8] J. Kaur, K. Griffin, B. Harrison, I.V. Kozhevnikov, J. Catal. 208 (2002) 448.

[9] E.F. Kozhevnikova, E.G. Derouane, I.V. Kozhevnikov, Chem. Commun. (2002) 1178.

[10] E.F. Kozhevnikova, J. Quartararo, I.V. Kozhevnikov, Appl. Catal. A 245 (2003) 69.

[11] S. Shikata, T. Okuhara, M. Misono, J. Mol. Catal. A 100 (1995) 49.

[12] S.S. Lim, G.I. Park, I.K. Song, W.Y. Lee, J. Mol. Catal. A 182 (2002) 175.

[13] R. Watanabe, T. Suzuki, T. Okuhara, Catal. Today 66 (2001) 123

[14] B.B. Bardin, R.J. Davis, Top. Catal. 6 (1998) 77.

[15] T. Matsuda, M. Sato, T. Kanno, H. Miura, K. Sugiyama, J. Chem. Soc. Faraday Trans. 77 (1981) 3107

[16] K.A. da Silva Rocha, I.V. Kozhevnikov, E.V. Gusevskaya, Appl. Catal. A 294(2005) 106.

[17] E.J.L. Lana, K.A. da Silva Rocha, I.V. Kozhevnikov, E.V. Gusevskaya, J. Mol. Catal. A 259 (2006) 99.

[18] K.A. da Silva Rocha, P.A. Robles-Dutenhefner, E.M.B. Sousa, E.F. Kozhevnikova, I.V. Kozhevnikov, E.V. Gusevskaya, Appl. Catal. A 317 (2007) 171.

[19] K.A. da Silva, P.A. Robles-Dutenhefner, E.M.B. Sousa, E.F. Kozhevnikova, I.V Kozhevnikov, E.V. Gusevskaya, Catal. Commun. 5 (2004) 425.

[20] K.A. da Silva Rocha, J.L. Hoehne, E.V. Gusevskaya, Chem. Eur. J. 14 (2008) 6166.

[21] W.E. Erman, Chemistry of the Monoterpenes. An Encyclopedic Handbook, Marcel Dekker, New York, 1985.

[22] K. Bauer, D. Garbe, H. Surburg, Common Fragrance and Flavor Materials: Preparation, Properties and Uses, Wiley, New York, 1997.

[23] D.H. Pybus, C.S. Sell (Eds.), The Chemistry of Fragrances, RSC Paperbacks, Cambridge, 1999.

[24] R.V. Jasra, B. Tyagi, M. K. Mishra, US Patent 7,132,582 (2006).

[25] B. Tyagi, M.K. Mishra, R.V. Jasra, Catal. Commun. 7 (2005) 52

[26] B. Singh, J. Patial, P. Sharma, S.G. Agarwal, G.N. Qazi, S. Maity, J. Mol Catal. A 266 (2007) 215.

[27] M. Gscheidmeier, H. Häberlein, H. H. Häberlein, J. T. Häberlein, M. C. Häberlein, US Patent 5,826,202 (1998). 
[28] A. Severino, A. Esculcas, J. Rocha, J. Vital, L.S. Lobo, Appl. Catal. A 142 (1996) 255.

[29] G. Gunduz, R. Dimitrova, S. Yilmaz, L. Dimotrov, Appl. Catal. A 282 (2005) 61.

[30] R. Rachwalik, Z. Olejniczak, J. Jiao, J. Huang, M. Hunger, B. Sulikwoski, J. Catal. 252 (2007) 161.

[31] M.Kr. Yadav, C.D. Chudasama, R.V. Jasra, J. Mol. Catal. A 216 (2004) 51.

[32] C. Volzone, O. Masini, N.A. Comelli, L.M. Grzona, E.N. Ponzi, M.I. Ponzi, Mater. Chem. Phys. 93 (2005) 296

[33] N.A. Comelli, E.N. Ponzi, M.I. Ponzi, Chem. Eng. J. 117 (2006) 161.

[34] O. Chimal-Valencia, A. Robau-Sánchez, V. Collins-Martínez, A. Aguilar-Elguézabal, Bioresour. Technol. 93 (2004) 119.
[35] N.A. Comelli, L.M. Grzona, O. Masini, E.N. Ponzi, M.I. Ponzi, J. Chil. Chem. Soc. 49 (2004) 245.

[36] A.D. Newman, A.F. Lee, K. Wilson, N.A. Young, Catal. Lett. 102 (2005) 45.

[37] R.E. Beyler, G. Ourisson, J. Org. Chem. 30 (1965 2838).

[38] R. Ranganathan, U.R. Nayak, T.S. Santhanakrishnan, SukhDev, Tetrahedron 26 (1970) 621.

[39] I.V. Kozhevnikov, A. Sinnema, A.J.A. van der Weerdt, H. van Bekkum, J. Mol. Catal. A 120 (1997) 63.

[40] E.F. Kozhevnikova, I.V. Kozhevnikov, J. Catal. 224 (2004) 164.

[41] F. Ebmeyer, J. Mol. Struct. (THEOCHEM) 582 (2002) 251. 